\title{
Diversity of activity participation determines bone mineral content in the lower limbs of pre-pubertal children with developmental coordination disorder
}

\author{
Shirley S.M. Fong ${ }^{1}$, Dana Vackova ${ }^{1}$, Anna W.M. Choi ${ }^{2}$, Yoyo T.Y. Cheng ${ }^{1}$, Timothy T.T. Yam ${ }^{1}$, X. Guo \\ ${ }^{1}$ School of Public Health, University of Hong Kong, Hong Kong \\ ${ }^{2}$ Department of Social Work and Social Administration, University of Hong Kong, Hong Kong \\ ${ }^{3}$ Department of Rehabilitation Sciences, Hong Kong Polytechnic University, Hong Kong
}

Corresponding author:

Shirley S.M. Fong

School of Public Health

University of Hong Kong

Pokfulam, Hong Kong

Tel: (852)28315260

Fax: (852)28551712

E-mail: smfong@hku.hk

\section{Acknowledgments}

The authors would like to thank Professor Tai Hing Lam for his research idea and advice, Ms Lily Yuen (senior physiotherapist, Heep Hong Society), Chinese YMCA of Hong Kong, Emmanuel Primary School Kowloon, Heep Yunn Primary School, HHCKLA Buddhist Wisdom Primary School, HKTA Yuen Yuen Institute Shek Wai Kok Primary School, Pun U Association Wah Yan Primary School, Si Yuan School of the Precious Blood, SKH Tin Shui Wai Ling Oi Primary School, St. Peter's Catholic Primary School and TWGHs Hok Shan School for enabling the recruitment of participants.

\section{Funding}

The work described in this paper was partially supported by a Health and Medical Research Fund (13142081) from the Food and Health Bureau of Hong Kong and an Early Career Scheme Grant (27100614) from the Research Grants Council of Hong Kong. 


\begin{abstract}
Summary

This study examined the relationships between activity participation and bone mineralization in children with developmental coordination disorder. Limited participation in physical, recreational, social, skill-based and selfimprovement activities contributed to lower bone mineral content. For improved bone health, these children should participate in a variety of activities, not only physical activities.

Introduction: Limited activity participation in children with developmental coordination disorder (DCD) may have a negative impact on bone mineral accrual. The objectives of this study were to compare bone mineralization and activity participation patterns of pre-pubertal children with DCD and those with typical development, and to determine the association between activity participation patterns and bone mineralization in children with DCD. Methods: Fifty-two children with DCD (mean age = 7.51 years) and 61 children with typical development (mean age $=7.22$ years) participated in the study. Appendicular and total body (less head) bone mineral content (BMC) and bone mineral density (BMD) were evaluated by a whole-body dual-energy X-ray absorptiometry scan. Activity participation patterns were assessed using the Children's Assessment of Participation and Enjoyment (CAPE) questionnaire.

Results: Children with DCD had lower appendicular and total body BMCs and BMDs than children with typical development overall $(p<0.05)$. They also had lower CAPE total activity and physical activity diversity scores $(p<$ 0.05). After accounting for the effects of age, sex, height, lean mass and fat mass, the total activity diversity score remained independently associated with leg BMC in children with DCD, explaining $5.1 \%$ of the variance ( $p=$ 0.030). However, the physical activity diversity score was no longer associated with leg BMC $(p=0.090)$. Conclusions: Diversity of activity participation and bone mineralization were lower in pre-pubertal children with DCD. Decreased total activity participation diversity was a contributing factor to lower BMC in the legs of children with DCD.
\end{abstract}

Keywords: Clumsy children, activity participation variety, bone mineralization, skeletal development 


\section{Introduction}

Developmental coordination disorder (DCD), which affects approximately $6 \%$ of primary school-aged children, is one of the most common neurodevelopmental motor disorders [1]. The motor deficits of DCD are often accompanied by a higher weight status [2] and less frequent and diverse activity participation [2, 3]. Activity participation, especially weight-bearing high impact physical activity participation, can stimulate osteogenesis and is essential for bone mass accumulation during childhood [4-7]. Gains in bone mass early in life can offset age-related bone loss and may reduce osteoporotic fracture in late adulthood [8]. A sedentary lifestyle in children with DCD may thus have a negative impact on bone mineral accrual toward the attainment of peak bone mass and predispose these children to osteopenia/osteoporosis later in life.

To date, only three research teams have made a preliminary exploration of skeletal health in younger individuals with DCD or probable DCD. Using quantitative ultrasonometry, our previous study first showed that pre-pubertal children with DCD had a significant delay (1.09 years) in skeletal development, which was defined as "chronological age - ultrasonic bone age" [9]. Using peripheral quantitative computed tomography (pQCT), Hands et al. [10] also showed that motor difficulties contributed to below-average bone strength and structure (pQCT mean $\mathrm{z}$ scores ranged from -0.70 to -1.00 at various radial and tibial sites) in developing individuals. In addition, the higher fracture incidence in their probable DCD cohort (26.9\%) compared to the normal population (3-9\%) indicates that there may be skeletal problems for these adolescents early in life [10]. Recently, Ireland and his research team carried out a longitudinal study and reported that impaired motor competence in childhood is associated with lower pQCT bone strength indices in adolescence [11]. The result is in line with their previous studies suggesting that later onset of independent walking (a gross motor delay) is associated with lower pQCT bone strength indices in early childhood [12] and in older adults [13]. Motor incompetence in childhood may hence present a risk factor for osteopenia/ osteoporosis later in life [11,13]. To conclude, these studies collectively suggested that motor deficits in children may compromise skeletal health across life and thus it is a concern of clinicians, health care professionals and parents. However, no study has yet examined bone mineralization—bone mineral content (BMC) and bone mineral density (BMD) - in specifically children with DCD (who are known to have poor motor competence) using the gold standard dual-energy X-ray absorptiometry (DXA). DXA has been recommended by the International Society for Clinical Densitometry for evaluating and monitoring of bone health in children. It has been widely used clinically in many countries and so data obtained by DXA could be very useful clinically [14].

It is well known that reduced mechanical loading of bone from decreased physical activity is one of the major risk factors for low BMC and BMD in children with developmental disorders [15-18]. Our previous study of children with DCD showed that limited activity participation intensity explained $28.0 \%$ of the variance in delay in skeletal development (chronological age - ultrasonic bone age) [9]. Neumeyer and her research team also reported that DXA-derived BMD is lower in peripubertal boys with autism spectrum disorders (a very common comorbid condition of DCD) and may be associated with lower physical activity level [18]. However, to the best of our knowledge, no study has established a direct link between total activity participation, DXA-derived BMC and BMD in children with DCD thus far. The objectives of this novel study were (1) to compare bone mineralization and activity participation patterns between children with DCD and those with typical development and (2) to determine whether activity participation patterns were associated with bone mineralization in children with DCD. We hypothesized that DXA-derived BMC and BMD values and activity participation levels would be lower in children with DCD than in children with typical development, and that lower activity participation levels would be associated with lower BMC and BMD among children with DCD.

\section{Methods \\ Participants}

This was a cross-sectional exploratory study. Between December 2015 and December 2016, a convenience sample of children with and without DCD was recruited from primary schools, parents' groups and local nongovernmental organizations with pediatric rehabilitation services via poster, WhatsApp and website advertising. Data collection and screening were performed by three experienced physiotherapists assisted by two trained research assistants in the Physical Activity Laboratory and DXA Laboratory of the University of Hong Kong and the Centre of Sports Training and Rehabilitation of the Hong Kong Polytechnic University. The inclusion criteria were (1) 6-10 years old, (2) in Tanner stage I as reported by the parents, (3) diagnosed with DCD (according to the Diagnostic and Statistical Manual of Mental Disorders V - presence of comorbid conditions such as attention deficit hyperactivity disorder, autism spectrum disorder, dyslexia and specific learning disorder were also included) [1], (4) a gross motor composite score of $\leq 42$ on the Bruininks-Oseretsky Test of Motor Proficiency [19] or a total impairment score of <5th percentile on the Movement Assessment Battery for Children (MABC) test [20], (5) a total 
score of $<46$ (for children aged between 5 years and 7 years 11 months), $<55$ (for children aged between 8 years and 9 years 11 months) or $<57$ (for children aged between 10 years and 15 years) on the DCD questionnaire 2007 [21], (6) Chinese ethnicity, (7) attending a mainstream primary school in Hong Kong, (8) normal intelligence and (9) able to follow instructions. The exclusion criteria were (1) diagnosed with psychiatric, congenital, genetic, endocrine, neurological, musculoskeletal or cardiopulmonary disorders that might have affected motor performance or skeletal development, (2) receiving active treatment, including complementary and alternative medicine, (3) demonstrating excessive disruptive behavior, (4) having a metallic implant or (5) a family history of bone diseases or genetic disorders.

Typically developing children in the control group were selected according to the same inclusion and exclusion criteria and were required to have no history of DCD and to pass the MABC test (i.e., a total impairment score of $>5$ th percentile) [20] and DCD questionnaire (i.e., a total score of $>46,>55$ or $>57$ depending on their chronological age) [21]. Ethical approval was obtained from the Human Research Ethics Committee of the University of Hong Kong. A full description of the study was given to the participants and their parents, who also provided written informed consent. All of the experimental procedures were conducted in accordance with the Declaration of Helsinki.

\section{Outcome measurements}

Bone mineralization

Each participant underwent a whole-body scan using a DXA scanner (Horizon A, Hologic Inc., Bedford, M.A., U.S.A.). All measurements were performed by two licensed operators following standardized procedures as described in the Hologic user manual [22]. To maintain the legs in an internal rotated position (i.e., the standard position) throughout the 3-minute scanning process, 3M micropore tape was placed around the two big toes. After the scan, the participants' total body (less head) and bilateral upper limb and lower limb BMCs (in g) and BMDs (in $\mathrm{g} / \mathrm{cm}^{2}$ ) were determined using the DXA scanner's region of interest program (the ruler tool function), and these variables were used in the outcome analyses. In addition, the total body lean mass, fat mass and percentage of body fat were reported as demographic data. The precision of the DXA scanner in vivo is excellent, with the coefficient of variation for whole-body and regional BMCs and BMDs ranging from 1\% to 2\% [23].

\section{Activity participation}

The Children's Assessment of Participation and Enjoyment (CAPE) questionnaire was completed via faceto-face interviews with each participant and parent. The CAPE questionnaire is a commonly used self-report measure of out-of-school activity participation patterns for young persons aged 6 through 21 years. The internal consistency, construct validity, content validity and test-retest reliability have been reported to be good [24, 25]. The questionnaire includes 55 activities categorized into 5 types: physical, skill-based, recreational, social and selfimprovement. Details of the activities are presented in Appendix 1. The physical and skill-based activities require specific physical abilities, whereas the recreational, social and self-improvement activities involve essential life-long general skills. CAPE measures the pattern of activity participation according to five dimensions: diversity, intensity, companionship, location and enjoyment. The diversity score represents the total number of activities the child has participated in over the previous 4 months. The intensity score indicates the participation frequency for a set of activities. The companionship score measures "with whom did the child do the activity most often," with lower scores indicating solitary activities and higher scores indicating more social engagement. The location score measures the proximity to home of the activity location, with lower scores indicating participation closer to home and higher scores indicating community-based participation. The enjoyment score measures how much the participant liked/enjoyed a particular activity, with the lowest score indicating "did not like it" and the highest score indicating "loved it" [26]. In this study, the total activity and physical activity diversity, intensity, companionship, location and enjoyment scores were used for analysis.

\section{Demographics}

Relevant information such as age and medical history was obtained by interviewing the participants and their parents and from medical records, if available. Skeletal maturity (bone age), which might have affected the children's BMCs and BMDs, was determined ultrasonically with a Sunlight BonAge system (Sunlight Medical Ltd., Tel Aviv, Israel). The detailed assessment procedures were described in our previous publication [9]. As both calcium and vitamin D absorption could affect BMC and BMD, dietary calcium intake and sunlight exposure (the principal source of vitamin D) were documented. Calcium intake (mg/day) was estimated using the Hong Kong Hospital Authority Hong Kong East Cluster's Nutrition Information website (http://www3.ha.org.hk/dic/nq_03.html). To estimate sunlight exposure, the average time each participant spent on 
outdoor activities (hours/week) in the past month was asked and documented. The motor ability of the participants was assessed using the standardized MABC tool, which has demonstrated good reliability and validity [20]. Body weight and height were also measured using a mechanical weight scale equipped with a height rod, and body mass index $\left(\mathrm{kg} / \mathrm{m}^{2}\right)$ was calculated.

\section{Statistical analyses}

The sample size was calculated using G*Power 3.1.0 (Franz Faul, University of Kiel, Germany). Based on a statistical power of 0.8 , a two-tailed alpha level of 0.05 and an effect size of 0.6 [9], the minimum sample size needed to detect a significant between-groups difference in the CAPE activity participation outcomes was 45 per group. Regarding the bone outcomes, our previous study revealed a large effect size of 0.9 [9]. Therefore, the minimum sample size needed was 21 per group. In the regression analysis, the correlation between CAPE activity participation outcomes and bone outcomes was fair to good $(\mathrm{r}=0.3-0.5)$ [9], which translated into a large effect size of 0.7. To model up to five variables at an effect size of 0.7, an alpha level of 0.05 (two-tailed) and a power of 0.8, a minimum of 25 children with DCD was needed.

Statistical analyses were performed using SPSS 20.0 software (IBM, Armonk, NY). A two-tailed significance level of 0.05 was set. Descriptive statistics were calculated for all demographic and outcome variables. The normality of the data was checked using the Kolmogorov-Smirnov test and/or a histogram. Independent t-tests and chi-square tests were performed to compare the continuous and categorical demographic variables, respectively, between the DCD and control groups. To avoid an inflation of type I error due to multiple between-group comparisons, multivariate analysis of covariance (MANCOVA) was conducted, incorporating (1) all appendicular BMC outcomes, (2) all appendicular BMD outcomes, (3) CAPE total activity outcomes, and (4) CAPE physical activity outcomes while adjusting for potential covariates (age, sex, height, lean mass and fat mass) $[8,27,28]$. Separate univariate analyses of covariance (covariates were age, sex, height, lean mass and fat mass) were performed to compare the total body BMC and BMD (less head) between the two groups.

Pearson's correlation coefficient ( $\mathrm{r}$ ) was used to explore the bivariate associations between the bone and activity participation outcomes among children with DCD. Multiple regression analyses (enter method) were then performed to identify the determinants of DXA-derived BMC in the lower limbs of children with DCD. Selection of predictors for the regression analysis was based on both biological relevance and the results of the bivariate correlation analyses. Chronological age, sex, height, lean mass and fat mass were first forced into the regression model, as these factors might have influenced BMC in the children [8, 27, 28]. Next, the CAPE diversity scores were entered into the model. To avoid the problem of multicollinearity, any predictors that had a tolerance value of $<0.1$ and a variance inflation factor of $>10$ were not included in the same regression model.

\section{Results}

\section{Participant characteristics}

Overall, 65 children with DCD and 119 children with typical development were screened. Only 52 children with DCD and 61 children with typical development were eligible to participate in the study and agreed to receive a DXA scan and fill in the CAPE questionnaire. The characteristics of the participants are presented in Table 1. The demographic data of the two groups were comparable, except that children with DCD had a higher MABC total impairment score $(p<0.001)$ and scored lower on the DCD questionnaire $2007(p=0.001)$. This was anticipated, as these scores were used to differentiate children with DCD from those without.

\section{Comparison of bone mineralization outcomes}

The multivariate analysis results revealed an overall significant difference in DXA-derived appendicular BMC (Hotelling's Trace $=0.113, \mathrm{~F}_{2,105}=5.921, p=0.004$ ) and BMD (Hotelling's Trace $=0.145, \mathrm{~F}_{2,105}=7.622, p=$ 0.001 ) between the DCD and control groups. When considering individual appendicular BMC and BMD outcomes, the between-groups difference remained significant for most of them $(p<0.05)$ except upper appendicular BMC ( $p$ $=0.150$ ). Children with DCD displayed 8.22-14.73\% lower appendicular BMCs and 5.4-37.58\% lower appendicular BMDs than the controls. The total body BMC $\left(\mathrm{F}_{1,106}=10.450, p=0.002\right)$ and total body BMD $\left(\mathrm{F}_{1,106}=\right.$ $10.496, p=0.002$ ) were $12.85 \%$ and $4.76 \%$ lower, respectively, in the DCD group than in the control group (Table 2). In addition, the effect sizes did not change substantially with and without adjustment for covariates (age, sex, height, lean mass and fat mass).

\section{Comparison of activity participation outcomes}

For the CAPE outcomes, the MANCOVA results showed that the physical activity scores differed between the DCD and control groups overall (Hotelling's Trace $=0.145, \mathrm{~F}_{5,91}=2.646, p=0.028$ ). Further analyses revealed 
that the physical activity diversity, intensity and enjoyment scores were $25.06 \%, 26.72 \%$ and $10.89 \%$ lower, respectively, in the DCD group than in the control group $(p<0.05)$. No significant between-groups difference was noted in the physical activity companionship score or location score $(p>0.05)$ (Table 2$)$.

For the CAPE total activity scores, the multivariate analysis result was not statistically significant (Hotelling's Trace $=0.075, \mathrm{~F}_{5,99}=1.481, p=0.203$ ) but revealed a medium to large effect size (partial eta-squared $=$ 0.070). Analysis of individual outcomes showed that the total activity diversity score was $11.81 \%$ lower in the DCD group than in the control group $(p<0.05)$. No significant between-group difference was found in the total activity intensity, companionship, location or enjoyment scores $(p>0.05)$. In addition, the effect sizes did not change substantially with and without adjustment for covariates (age, sex, height, lean mass and fat mass) (Table 2).

\section{Association between bone mineralization and activity participation outcomes}

As only the BMC and BMD measures and CAPE diversity and intensity scores differed between groups overall, we focused on these outcomes in the subsequent correlational analyses. We did not analyze sex subgroups separately, as the sex differences in bone indices and activity participation diversity and intensity patterns were minimal in general (Table 2). Bivariate correlation analyses showed that BMC in the lower limbs was positively correlated with CAPE total activity diversity score $(r=0.320, p=0.021)$ and physical activity diversity score $(\mathrm{r}=$ $0.296, p=0.033$ ) in children with DCD. Therefore, in the first regression model, the CAPE total activity diversity score was used to predict BMC in the lower limbs of children with DCD. After accounting for the effects of age, sex, height, lean mass and fat mass, the CAPE total activity diversity score remained independently associated with BMC in the lower limbs, explaining $5.1 \%$ of its variance $(p=0.030)$. In the second regression model, the CAPE physical activity diversity score was used to predict BMC in the lower limbs in children with DCD. After adjusting for the effects of age, sex, height, lean mass and fat mass, the association of CAPE physical activity diversity score and BMC in the lower limbs was no longer significant $(p=0.090)$ (Table 3).

\section{Discussion}

To the best of our knowledge, this is the first study to show that pre-pubertal children with DCD had lower DXA-derived appendicular and total body BMC (except BMC of the upper limbs) and BMD than children with typical development. This is a cause for concern, as childhood is an important period of life for bone mass accumulation. Poor bone accrual inhibits the achievement of peak bone mass, which is usually attained in early adulthood [4], predisposes individuals to osteopenia/osteoporosis and increases fracture risk later in life [8, 10, 11, 13].

As the etiology of DCD is associated with neuropathology such as cerebellar and basal ganglia dysfunctions [29], it is unlikely that brain dysfunction directly impairs bone mineral metabolism. Studies have suggested several factors that may be responsible for a reduction in BMC/BMD in children with neurological disorders [30, 31]. These include undernourishment, insufficient calcium and vitamin D intake, side effects of medications [31], insufficient lean mass [32] and less participation in physical activity [30]. Our DCD and control groups had similar calcium intake and vitamin D absorption, and methylphenidate (Ritalin and Concerta) medication have no direct side effects on the developing musculoskeletal system [33]. As such, it was likely that lower physical activity participation level affected bone mineral metabolism in the children with DCD.

Indeed, the CAPE total activity diversity score and physical activity diversity, intensity and enjoyment scores were lower in the children with DCD than in the typically developing control group. These findings are in agreement with our and other research teams' studies showing that children with DCD had less diverse and less intense activity participation, particularly physical activity participation, than their typically developing peers [2, 3, 34, 35]. Contributing factors included motor incompetence, higher weight status [2, 3], and lower generalized selfefficacy in physical activity in children with DCD [34]. Self-perceptions of enjoyment in children with DCD could also affect decisions about whether to continue to participate in activities [36]. Our DCD group reported a lower level of enjoyment in physical activities. This may further explain the lower total activity participation diversity and physical activity participation diversity and intensity in children with DCD.

The present study (new data) confirmed our previous findings [2] that the CAPE total activity and physical activity companionship scores and location scores were similar for children with DCD and those with typical development. Both groups of children participated in activities with their parents and family members. This may be a reflection of the Asian cultural emphasis on parental warmth [37]. Regarding the activity location, neither group of children experienced any community access restrictions in the local community [2].

The most important findings of the present study were that the diversity (variety) of activity participation explained 5.1\% of the variance in lower limb BMC in pre-pubertal children with DCD (regression model 1). Participation in those activities defined as physical activities by CPAE alone may not be sufficient to improve lower 
limb BMC in this group of children (regression model 2). This means that children with DCD should participate in various types of activity including physical, recreational, social, skill-based and self-improvement activities to improve BMC in the lower limbs. These findings are not entirely surprising, as all CAPE activity types involve weight-bearing or even impact exercises (e.g., recreational activity such as going for a walk or a hike; social activity such as going on a full-day outing; skill-based activities such as doing gymnastics and dancing; and selfimprovement activity such as doing a chore) [25]. It is widely acknowledged that weight-bearing and impact exercises (where the bones deal with forces imposed in different directions) can increase the mechanical/impact loading of the lower limb bones and thus can stimulate skeletal mineralization, enhancing bone mineral accrual, BMC and BMD in children and young people [5, 6, 38-40]. In contrast, some physical activities are non-weightbearing or low-impact in nature (e.g., water sports and fishing) [25]. These types of low-impact physical activity, which load the skeleton primarily through muscular contractions, are known to have less influence on bone mass [5]. This may explain why participation in a variety of CAPE physical activities was not a significant predictor of lower limb BMC in children with DCD.

Although new significant findings are reported here, some limitations of this study should be addressed in future research work. First, our regression model accounted for only 5.1\% of the variance in lower limb BMC. Further studies should explore other factors that may adversely affect bone mineralization in pre-pubertal children with DCD, such as lower muscle strength [41], poor bone growth and reduction in bone turnover [9, 42]. Second, physical activity intensity and diversity were measured subjectively using the CAPE questionnaire. This questionnaire does not provide specific bone-loading information of different physical activities and may explain the weak physical activity-bone associations found in this study. A future study could measure physical activity objectively by using accelerometry or the bone-specific physical activity questionnaire [43]. The impact loading of the lower limb bones induced by various types of activity could also be estimated using the accelerometry [7] or a force platform. Third, regional BMC and BMD measurements using DXA may not be as sensitive as other measures such as those measured by pQCT or site-specific measures with DXA (i.e., radius or hip) [22, 23, 44]. Further study may use pQCT to measure the peripheral BMC and BMD of children with DCD instead. Fourth, due to the crosssectional design of the present study, a causal relationship between activity participation and BMC could not be established. A randomized controlled trial is needed to confirm the effects of participation in physical, recreational, social, skill-based and self-improvement activities on bone mineralization in children with DCD. Fifth, our data was obtained from children with DCD, and thus the results may not be generalizable to children with other types of disability (e.g., cerebral palsy). Finally, since half of the children in the DCD group had comorbid autism spectrum disorder, a condition that is known to compromise bone density [18], these children might have confounded the results. Nevertheless, results of this study may inform the design of early life bone-strengthening interventions for children with DCD. Such interventions should include a variety of activities that load the lower limb bones in different directions in addition to building generalized self-efficacy toward physical activity [45].

\section{Conclusions}

Bone mineralization and activity participation diversity were lower in children with DCD than in typically developing children. After accounting for the effects of age, sex, height, lean mass and fat mass, total activity participation diversity accounted for 5.1\% of the variance in lower limb BMC in children with DCD. In addition, participation in physical activities alone may not be sufficient to improve lower limb BMC in this group of children. Therefore, children with DCD should be encouraged to participate in a variety of activities, not limited to physical activities, to improve bone mineralization during their pre-pubertal years. These results may also be useful in designing early life bone-strengthening interventions for children with DCD.

\section{Compliance with ethical standards}

This study was approved by the Human Research Ethics Committee of the University of Hong Kong.

\section{Conflict of interest}

Shirley S.M. Fong, Dana Vackova, Anna W.M. Choi, Yoyo T.Y. Cheng, Timothy T.T. Yam, and X. Guo declare that they have no conflict of interest. 


\section{References}

1. APA (2013) Diagnostic and Statistical Manual of Mental Disorders. American Psychiatric Association, Arlington, VA

2. Fong SSM, Lee VYL, Chan NNC, Chan RSH, Chak WK, Pang MYC (2011) Motor ability and weight status are determinants of out-of-school activity participation for children with developmental coordination disorder. Res Dev Disabil 32:2614-2623

3. Fong SSM, Lee VYL, Pang MYC (2011) Sensory organization of balance control in children with developmental coordination disorder. Res Dev Disabil 32:2376-2382

4. Bonjour JP, Theintz G, Buchs B, Slosman D, Rizzoli R (1991) Critical years and stages of puberty for spinal and femoral bone mass accumulation during adolescence. J Clin Endocrinol Metab 73:555-563

5. Grimston SK, Willows ND, Hanley DA (1993) Mechanical loading regime and its relationship to bone mineral density in children. Med Sci Spots Exerc 25:1203-1210

6. Hind K, Burrows M (2007) Weight-bearing exercise and bone mineral accrual in children and adolescents: A review of controlled trials. Bone 40:14-27

7. Janz KF, Letuchy EM, Eichenberger Gilmore JM, Burns TL, Torner JC, Willing MC, Levy SM (2010) Early physical activity provides sustained bone health benefits later in childhood. Med Sci Sports Exerc 42:10721078

8. Bachrach LK (1993) Bone mineralization in childhood and adolescence. Curr Opin Pediatr 5:467-473

9. Tsang WWN, Guo X, Fong SSM, Mak KK, Pang MYC (2012) Activity participation intensity is associated with skeletal development in pre-pubertal children with developmental coordination disorder. Res Dev Disabil 33:1898-1904

10. Hands B, Chivers P, McIntyre F, Bervenotti FC, Blee T, Beeson B, Bettenay F, Siafarikas A (2015) Peripheral quantitative computed tomography (pQCT) reveals low bone mineral density in adolescents with motor difficulties. Osteoporos Int 26:1809-1818

11. Ireland A, Sayers A, Deere KC, Emond A, Tobias JH (2016) Motor competence in early childhood is positively associated with bone strength in late adolescence. J Bone Miner Res 31:1089-1098

12. Ireland A, Rittweger J, Schonau E, Lamberg-Allardt C, Viljakainen H (2014) Time since onset of walking predicts tibial bone strength in early childhood. Bone 68:76-84

13. Ireland A, Muthuri S, Rittweger J, Adams JE, Ward KA, Kuh D, Cooper R (2017) Later age at onset of independent walking is associated with lower bone strength at fracture-prone sites in older men. J Bone Miner Res 32:1209-1217

14. Bianchi ML, Baim S, Bishop NJ, Gordon CM, Hans DB, Langman CB, Leonard MB, Kalkwarf HJ (2010) Official positions of the International Society for Clinical Densitometry (ISCD) on DXA evaluation in children and adolescents. Pediatr Nephrol 25:37-47

15. Ausili E, Focarelli B, Tabacco F, Fortunelli G, Caradonna P, Massimi L, Sigismondi M, Salvaggio E, Rendeli C (2008) Bone mineral density and body composition in a myelomeningocele children population: effects of walking ability and sport activity. Eur Rev Med Pharmacol Sci 12:349-354

16. Hough JP, Boyd RN, Keating JL (2010) Systematic review of interventions for low bone mineral density in children with cerebral palsy. Pediatr 125:e670-e678

17. Soden SE, Garrison CB, Egan AM, Beckwith AM (2012) Nutrition, physical activity, and bone mineral density in youth with autistic spectrum disorders. J Dev Behav Pediatr 33:618-624

18. Neumeyer AM, Gates A, Ferrone C, Lee H, Misra M (2013) Bone density in peripubertal boys with autism spectrum disorders. J Autism Dev Disord 43:1623-1629

19. Bruininks RH (1978) Bruininks-Oseretsky Test of Motor Proficiency: Examiner’s Manual. American Guidance Service, Circle Pines, MN

20. Henderson SE, Sugden DA (1992) Movement Assessment Battery for Children Manual. The Psychological Corporation Ltd., London

21. Wilson BN, Crawford SG, Green D, Roberts G, Aylott A, Kaplan BJ (2009) Psychometric properties of the revised developmental coordination disorder questionnaire. Phys Occup Ther Pediatr 29:182-202

22. Hologic Inc (2015) Horizon QDR Series User Guide. Hologic Inc., Bedford, MA, USA

23. Spector E, LeBlanc A, Shackelford L (1995) Hologic QDR 2000 whole-body scans: A comparison of three combinations of scan modes and analysis software. Osteoporos Int 5:440-445

24. Imms C (2008) Review of the Children's Assessment of Participation and Enjoyment and the Preferences for Activity of Children. Phys Occup Ther Pediatr 28:389-404

25. King GA, Law M, King S, Hurley P, Hanna S, Kertoy M, Rosenbaum P (2006) Measuring children’s participation in recreation and leisure activities: Construct validation of the CAPE and PAC. Child Care Health Dev 33:28-39 
26. King G, Law M, King S, Hurley P, Rosenbaum P, Hanna S, Kertoy M, Young N (2004) Children’s Assessment of Participation and Enjoyment and Preferences for Activities of Children (CAPE/PAC). Harcourt Assessment, San Antonio, Texas

27. Rauchenzauner M, Schmid A, Heinz-Erian P, Kapelari K, Falkensammer G, Griesmacher A, Finkenstedt G, Hogler W (2007) Sex- and age-specific reference curves for serum markers of bone turnover in healthy children from 2 months to 18 years. J Clin Endocrinol Metab 92:443-449

28. Joseph S, McCarrison S, Wong SC (2016) Skeletal fragility in children with chronic disease. Horm Res Paediatr 86:71-82

29. Zwicker JG, Missiuna C, Boyd LA (2009) Neural correlates of developmental coordination disorder: A review of hypotheses. J Child Neurol 24:1273-1281

30. Ekhlaspour L, Baskaran C, Campoverde KJ, Sokoloff NC, Neumeyer AM, Misra M (2016) Bone density in adolescents and young adults with autism spectrum disorders. J Autism Dev Disord 46:3387-3391

31. Sharawat IK, Sitaraman S (2016) Skeletal maturation and mineralisation of children with moderate to severe spastic quadriplegia. J Clin Diagn Res 10:SC01-SC05

32. Janz KF, Burns TL, Levy SM, Torner JC, Willing MC, Beck TJ, Gilmore JM, Marshall TA (2004) Everyday activity predicts bone geometry in children: The Iowa bone development study. Med Sci Sports Exerc 36:11241131

33. MIMS (2015) MIMS Hong Kong. Havas MediMedia, Hong Kong

34. Cairney J, Hay JA, Faught BE, Wade TJ, Corna L, Flouris A (2005) Developmental coordination disorder, generalized self-efficacy toward physical activity, and participation in organized and free play activities. J Pediatr 147:515-520

35. Magalhaes LC, Cardoso AA, Missiuna C (2011) Activities and participation in children with developmental coordination disorder: A systematic review. Res Dev Disabil 32:1309-1316

36. Cairney J, Hay J, Mandigo J, Wade T, Faught BE, Flouris A (2007) Developmental coordination disorder and reported enjoyment of physical education in children. Eur Phys Educ Rev 13:81-98

37. Kim SY, Wong VY (2002) Assessing Asian and Asian American parenting: A review of the literature. In: Kurasaki K, Okazaki S, Sue S (ed) Asian American Mental Health: Assessment Methods and Theories. Kluwer Academic Publishers, Netherlands, pp 185-203

38. Fuchs RK, Bauer JJ, Snow CM (2001) Jumping improves hip and lumbar spine bone mass in prepubescent children: A randomized controlled trial. J Bone Miner Res 16:148-156

39. Nikander R, Sievanen H, Heinonen A, Kannus P (2005) Femoral neck structure in adult female athletes subjected to different loading modalities. J Bone Miner Res 20:520-528

40. Nikander R, Sievanen H, Uusi-Rasi K, Heinonen A, Kannus P (2006) Loading modalities and bone structures at nonweight-bearing upper extremity and weight-bearing lower extremity: A pQCT study of adult female athletes. Bone 39:886-894

41. Chen CL, Lin KC, Wu CY, Ke JY, Wang CJ, Chen CY (2012) Relationships of muscle strength and bone mineral density in ambulatory children with cerebral palsy. Osteoporos Int 23:715-721

42. Mora S, Pitukcheewanont P, Kaufman FR, Nelson JC, Gilsanz V (1999) Biochemical markers of bone turnover and the volume and the density of bone in children at different stages of sexual development. J Bone Miner Res 14:1664-1671

43. Weeks BK, Beck BR (2008) The BPAQ: a bone-specific physical activity assessment instrument. Osteoporos Int 19:1567-1577

44. Lewiecki EM, Gordon CM, Baim S, Leonard MB, Bishop NJ, Bianchi ML, Kalkwarf HJ, Langman CB, Plotkin H, Rauch F, Zemel BS, Binkley N, Bilezikian JP, Kendler DL, Hans DB, Silverman S (2008) International Society for Clinical Densitometry 2007 adult and pediatric official positions. Bone 43:1115-1121

45. Cairney J, Hay JA, Faught BE, Wade TJ, Corna L, Flouris A (2005) Developmental coordination disorder, generalized self-efficacy toward physical activity, and participation in organized and free play activities. J Pediatr $147: 515-520$ 


\section{Tables}

Table 1 Characteristics of participants

\begin{tabular}{|c|c|c|c|}
\hline & $\begin{array}{l}\text { DCD group } \\
\quad(n=52)\end{array}$ & $\begin{array}{l}\text { Control group } \\
\qquad(\mathrm{n}=61)\end{array}$ & $p$ value \\
\hline Age, year & $7.5 \pm 1.1$ & $7.2 \pm 1.0$ & 0.142 \\
\hline Sex (male/female), $\mathrm{n}$ & 43 / 9 & 48 / 13 & 0.592 \\
\hline Weight, kg & $26.5 \pm 6.7$ & $24.7 \pm 5.8$ & 0.132 \\
\hline Height, cm & $125.2 \pm 8.4$ & $123.3 \pm 8.4$ & 0.228 \\
\hline Body mass index, kg/m² & $16.8 \pm 2.8$ & $16.1 \pm 2.2$ & 0.152 \\
\hline $\begin{array}{l}\text { DXA-derived total body lean } \\
\text { mass, kg }\end{array}$ & $16.1 \pm 3.0$ & $17.3 \pm 3.8$ & 0.071 \\
\hline $\begin{array}{l}\text { DXA-derived total body fat } \\
\text { mass, kg }\end{array}$ & $8.1 \pm 3.2$ & $8.7 \pm 2.9$ & 0.317 \\
\hline $\begin{array}{l}\text { DXA-derived percentage of } \\
\text { body fat, } \%\end{array}$ & $31.5 \pm 5.5$ & $31.4 \pm 4.4$ & 0.905 \\
\hline $\begin{array}{l}\text { Movement Assessment } \\
\text { Battery for Children total } \\
\text { impairment score }\end{array}$ & $18.4 \pm 10.4$ & $5.2 \pm 2.5$ & $<0.001^{*}$ \\
\hline $\begin{array}{l}\text { DCD questionnaire } 2007 \text { total } \\
\text { score }\end{array}$ & $36.3 \pm 9.6$ & $42.5 \pm 9.3$ & $0.001^{*}$ \\
\hline $\begin{array}{l}\text { Bone age (skeletal maturity), } \\
\text { year }\end{array}$ & $7.2 \pm 1.7$ & $7.3 \pm 1.8$ & 0.585 \\
\hline Calcium intake, mg/day & $741 \pm 212$ & $733 \pm 78$ & 0.780 \\
\hline $\begin{array}{l}\text { Time spent in outdoor } \\
\text { activities (sunlight exposure), } \\
\text { hours/week }\end{array}$ & $4.1 \pm 1.3$ & $4.0 \pm 0.3$ & 0.492 \\
\hline \multicolumn{4}{|l|}{ Comorbidity, n (\%) } \\
\hline $\begin{array}{l}\text { Attention deficit } \\
\text { hyperactivity disorder }\end{array}$ & $13(25 \%)$ & --- & \\
\hline Dyslexia & 7 (13.46\%) & --- & \\
\hline Autism spectrum disorder & $26(50.00 \%)$ & --- & \\
\hline No comorbidity & $6(11.54 \%)$ & --- & \\
\hline \multicolumn{4}{|c|}{ Medications for attention deficit hyperactivity disorder, n (\%) } \\
\hline Ritalin & $4(7.69 \%)$ & --- & \\
\hline Concerta & $1(1.92 \%)$ & --- & \\
\hline Unknown & $2(3.85 \%)$ & --- & \\
\hline
\end{tabular}

Means \pm standard deviations are presented unless otherwise specified. $* p<0.05$. 
Table 2 Outcome measures for children with DCD and children with typical development

\begin{tabular}{|c|c|c|c|c|c|c|}
\hline & \multicolumn{2}{|c|}{$\begin{array}{c}\text { DCD group } \\
(\mathrm{n}=52) \\
\end{array}$} & \multicolumn{2}{|c|}{$\begin{array}{c}\text { Control group } \\
(\mathrm{n}=61) \\
\end{array}$} & \multirow[t]{2}{*}{$p$ value } & \multirow[t]{2}{*}{ Effect size } \\
\hline & $\begin{array}{l}\text { Unadjusted mean } \pm \\
\text { standard deviation }\end{array}$ & $\begin{array}{c}\text { Adjusted mean } \pm \\
\text { standard error } \\
\text { (95\% confidence interval) }\end{array}$ & $\begin{array}{l}\text { Unadjusted mean } \pm \\
\text { standard deviation }\end{array}$ & $\begin{array}{c}\text { Adjusted mean } \pm \\
\text { standard error } \\
\text { (95\% confidence interval) }\end{array}$ & & \\
\hline \multicolumn{7}{|c|}{ DXA-derived bone mineral content, g } \\
\hline Upper limbs & $83.02 \pm 14.75$ & $85.34 \pm 1.57(82.23,88.46)$ & $90.46 \pm 18.39$ & $88.48 \pm 1.45(85.61,91.35)$ & 0.150 & 0.019 \\
\hline Lower limbs & $242.89 \pm 63.69$ & $\begin{array}{c}251.13 \pm 5.86(239.51 \\
262.76)\end{array}$ & $284.85 \pm 56.31$ & $\begin{array}{c}277.83 \pm 5.40(267.12 \\
288.54)\end{array}$ & $0.001 *$ & 0.093 \\
\hline $\begin{array}{l}\text { Total body (less } \\
\text { head) }\end{array}$ & $513.37 \pm 88.72$ & $\begin{array}{c}530.01 \pm 10.08(510.02 \\
549.99)\end{array}$ & $589.08 \pm 120.00$ & $\begin{array}{c}574.89 \pm 9.29(556.48 \\
593.30)\end{array}$ & $0.002 *$ & 0.090 \\
\hline \multicolumn{7}{|c|}{ DXA-derived bone mineral density, $\mathrm{g} / \mathrm{cm}^{2}$} \\
\hline Upper limbs & $0.87 \pm 0.09$ & $0.88 \pm 0.01(0.87,0.90)$ & $0.92 \pm 0.10$ & $0.91 \pm 0.01(0.89,0.92)$ & $0.012 *$ & 0.058 \\
\hline Lower limbs & $1.22 \pm 0.15$ & $1.24 \pm 0.01(1.22,1.26)$ & $1.32 \pm 0.14$ & $1.30 \pm 0.01(1.28,1.32)$ & $<0.001 *$ & 0.125 \\
\hline $\begin{array}{l}\text { Total body (less } \\
\text { head) }\end{array}$ & $0.60 \pm 0.05$ & $0.60 \pm 0.01(0.58,0.61)$ & $0.63 \pm 0.06$ & $0.63 \pm 0.01(0.62,0.65)$ & $0.002 *$ & 0.090 \\
\hline \multicolumn{7}{|l|}{ CAPE total activity } \\
\hline Diversity score & $24.71 \pm 6.81$ & $25.01 \pm 1.02(22.98,27.03)$ & $28.02 \pm 7.38$ & $27.78 \pm 0.91(26.00,29.59)$ & $0.048 *$ & 0.037 \\
\hline Intensity score & $1.85 \pm 0.57$ & $1.86 \pm 0.08(1.70,2.02)$ & $2.07 \pm 0.53$ & $2.06 \pm 0.07(1.92,2.20)$ & 0.064 & 0.033 \\
\hline $\begin{array}{l}\text { Companionship } \\
\text { score }\end{array}$ & $2.40 \pm 0.43$ & $2.41 \pm 0.07(2.27,2.54)$ & $2.43 \pm 0.48$ & $2.43 \pm 0.06(2.31,2.55)$ & 0.767 & 0.001 \\
\hline Location score & $2.90 \pm 0.55$ & $2.91 \pm 0.09(2.73,3.08)$ & $2.89 \pm 0.66$ & $2.89 \pm 0.08(2.73,3.04)$ & 0.847 & $<0.001$ \\
\hline Enjoyment score & $3.55 \pm 0.60$ & $3.54 \pm 0.10(3.35,3.73)$ & $3.73 \pm 0.68$ & $3.74 \pm 0.09(3.57,3.90)$ & 0.135 & 0.022 \\
\hline \multicolumn{7}{|c|}{ CAPE physical activity } \\
\hline Diversity score & $3.14 \pm 1.59$ & $3.16 \pm 0.30(2.55,3.76)$ & $4.19 \pm 2.23$ & $4.18 \pm 0.26(3.65,4.70)$ & $0.014 *$ & 0.062 \\
\hline Intensity score & $0.85 \pm 0.58$ & $0.85 \pm 0.09(0.68,1.02)$ & $1.16 \pm 0.54$ & $1.16 \pm 0.08(1.01,1.31)$ & $0.010 *$ & 0.068 \\
\hline $\begin{array}{l}\text { Companionship } \\
\text { score }\end{array}$ & $2.90 \pm 0.99$ & $2.89 \pm 0.15(2.60,3.18)$ & $3.15 \pm 0.90$ & $3.16 \pm 0.13(2.91,3.41)$ & 0.172 & 0.020 \\
\hline Location score & $4.27 \pm 1.15$ & $4.28 \pm 0.18(3.93,4.63)$ & $4.03 \pm 1.13$ & $4.02 \pm 0.15(3.72,4.33)$ & 0.279 & 0.012 \\
\hline Enjoyment score & $3.52 \pm 1.02$ & $3.53 \pm 0.14(3.25,3.81)$ & $3.95 \pm 0.85$ & $3.94 \pm 0.12(3.70,4.19)$ & $0.031^{*}$ & 0.048 \\
\hline
\end{tabular}

Adjusted means: covariates included age, sex, height, total body lean mass and fat mass.

${ }^{*} p<0.05$. 
Table 3 Multiple regression analyses for predicating bone mineral content in the lower limbs in children with DCD ( $\mathrm{n}=52$ )

\begin{tabular}{|c|c|c|c|c|c|c|c|c|c|}
\hline Model & Predictors & 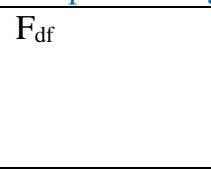 & $\mathrm{R}^{2}$ & Adjusted $\mathrm{R}^{2}$ & $\mathrm{R}^{2}$ change & $\begin{array}{l}\text { Unstandardized } \\
\text { regression } \\
\text { coefficient (B) }\end{array}$ & $\begin{array}{l}\text { 95\% confidence } \\
\text { interval for B }\end{array}$ & $\begin{array}{l}\text { Standardized } \\
\text { regression } \\
\text { coefficient } \\
(\beta) \\
\end{array}$ & $p$ value \\
\hline \multicolumn{10}{|c|}{ Dependent variable: DXA-derived bone mineral content of lower limbs } \\
\hline Model 1 & & $\begin{array}{l}\mathrm{F}_{6,45}=8.821 \\
p<0.001^{*}\end{array}$ & 0.540 & 0.479 & & & & & \\
\hline & Chronological age & & & & & -2.517 & $-19.890,14.856$ & -0.042 & 0.772 \\
\hline & Sex & & & & 0.004 & 1.216 & $-34.900,37.332$ & 0.007 & 0.946 \\
\hline & Height & & & & 0.001 & -0.317 & $-2.619,1.985$ & -0.042 & 0.783 \\
\hline & Lean mass & & & & 0.476 & 0.013 & $0.006,0.020$ & 0.615 & $<0.001 *$ \\
\hline & Fat mass & & & & $<0.001$ & 0.001 & $-0.005,0.008$ & 0.060 & 0.716 \\
\hline & $\begin{array}{l}\text { CAPE total } \\
\text { activity diversity } \\
\text { score }\end{array}$ & & & & 0.051 & 2.245 & $0.226,4.264$ & 0.238 & $0.030 *$ \\
\hline \multirow[t]{7}{*}{ Model 2} & & $\begin{array}{l}\mathrm{F}_{6,45}=8.162 \\
p<0.001^{*}\end{array}$ & 0.521 & 0.457 & & & & & \\
\hline & Chronological age & & & & & -1.815 & $-19.519,15.889$ & -0.030 & 0.837 \\
\hline & Sex & & & & 0.004 & 9.652 & $-26.437,45.740$ & 0.058 & 0.593 \\
\hline & Height & & & & 0.001 & -0.556 & $-2.887,1.774$ & -0.074 & 0.633 \\
\hline & Lean mass & & & & 0.476 & 0.014 & 0.007, 0.021 & 0.644 & $<0.001 *$ \\
\hline & Fat mass & & & & $<0.001$ & $<0.001$ & $-0.006,0.007$ & 0.019 & 0.910 \\
\hline & $\begin{array}{l}\text { CAPE physical } \\
\text { activity diversity } \\
\text { score }\end{array}$ & & & & 0.032 & 6.228 & $-1.019,13.475$ & 0.182 & 0.090 \\
\hline
\end{tabular}

$* p<0.05$. 
Appendix 1 Children's Assessment of Participation and Enjoyment activity types [25]

\begin{tabular}{|c|c|c|c|c|}
\hline Physical activities & Recreational activities & Social activities & Skill-based activities & Self-improvement activities \\
\hline Doing martial arts & Playing with pets & Hanging out & Doing gymnastics & Doing volunteer work \\
\hline Racing or track and field & Taking care of a pet & Going to the movies & Horseback riding & Doing a chore \\
\hline Playing non-team sports & Going for a walk or a hike & Going on a full-day outing & Learning to dance & Shopping \\
\hline $\begin{array}{l}\text { Doing individual physical } \\
\text { activities }\end{array}$ & Doing puzzles & Talking on the phone & Dancing & Doing homework \\
\hline Fishing & Playing board or card games & Going to a party & Swimming & Writing letters \\
\hline Gardening & $\begin{array}{l}\text { Doing crafts, drawing or } \\
\text { coloring }\end{array}$ & Visiting & Learning to sing & Writing a story \\
\hline Playing games & Collecting things & Entertaining others & Taking art lessons & $\begin{array}{l}\text { Getting extra help for } \\
\text { schoolwork from a tutor }\end{array}$ \\
\hline $\begin{array}{l}\text { Bicycling, in-line skating, or } \\
\text { skateboarding }\end{array}$ & $\begin{array}{l}\text { Playing computer or video } \\
\text { games }\end{array}$ & Going to a live event & Playing a musical instrument & Doing a religious activity \\
\hline Participating in school clubs & $\begin{array}{l}\text { Doing pretend or imaginary } \\
\text { play }\end{array}$ & Listening to music & Taking music lessons & Going to the public library \\
\hline Doing team sports & Playing with things or toys & Making food & $\begin{array}{l}\text { Participating in community } \\
\text { organizations }\end{array}$ & Reading \\
\hline Doing water sports & Playing on equipment & & & \\
\hline Doing snow sports & $\begin{array}{l}\text { Watching TV or a rented } \\
\text { movie }\end{array}$ & & & \\
\hline Doing a paid job & & & & \\
\hline
\end{tabular}

